\title{
Primeira REFERÊNCIA de Plantas gaMetofíticas EM Spermothamaion nonatoi (Ceramiales, Rhodophyta)
}

\author{
José Marcos de Castro Nunes ${ }^{1,2,3}$ \& Silvia Maria Pita de Beauclair Guimarães ${ }^{4}$
}

\begin{abstract}
Resumo
(Primeira referência de plantas gametofíticas em Spermothamnion nonatoi (Ceramiales, Rhodophyta)) Durante estudo sobre as rodofíceas do litoral do estado da Bahia foram encontrados exemplares gametofíticos e esporofíticos de Spermothamnion nonatoi A.B. Joly. O material estudado é proveniente de diferentes coletas realizadas no médio e infralitoral. Apesar da espécie ter sido citada para várias regiões do litoral brasileiro, somente plantas inférteis ou esporofíticas haviam sido encontradas. Este trabalho apresenta descrição e ilustrações das estruturas masculinas e femininas da espécie.
\end{abstract}

Palavras-chave: biodiversidade, plantas sexuadas, Bahia, Brasil.

\section{Abstract}

(First reference of gametophytic plants in Spermothamnion nonatoi (Ceramiales, Rhodophyta)) During studies on Rhodophyta from the coastline of Bahia State, gametophytic and sporophytic specimens of Spermothamnion nonatoi A.B. Joly were found. The specimens were collected in the midlittoral and infralittoral zone. Although this species was referred from many regions of the Brazilian coast, only infertile or sporophytic specimens have been found. The present paper presents the description and illustrations of the male and female structures of the species.

Key words: biodiversity, sexual plants, Bahia, Brazil.

\section{INTRODUÇão}

O gênero Spermothamnion Aresch. pertence à ordem Ceramiales, tribo Spermothamnieae Schmitz. Os gêneros desta tribo são morfologicamente semelhantes entre si, apresentando talo diminuto constituído por filamentos unisseriados, eixos prostrados portando rizóides e filamentos eretos esparsamente ramificados e procarpos originados nas células subapicais dos ramos férteis. Os gêneros são separados com base na presença ou ausência de um invólucro no carposporófito, número de células auxiliares e número de células periaxiais por segmento fértil (Gordon 1972).

Os gêneros Ptilothamnion Thuret ex Le Jolis, Spermothamnion Aresch. e Tiffaniella Doty \& Meñez são muito próximos. Contudo, diferem principalmente em detalhes do desenvolvimento do carposporófito (Gordon 1972; Womersley 1998). Em Ptilothamnion, o carposporófito desenvolve-se a partir de uma célula auxiliar única. A célula hipógina, a qual não é incorporada pela célula de fusão, é bem mais longa que a célula subapical e produz dois filamentos involucrais. Em Spermothamnion, o carposporófito desenvolve-se a partir de duas células auxiliares, a célula hipógina é só levemente mais longa que a célula subapical e os filamentos involucrais são produzidos a partir da célula subhipógina. Gordon (1972) descreve que em Spermothamnion, forma-se no carposporófito maduro uma célula de fusão bem definida englobando as células basais dos gonimoblastos, a célula subapical e a célula hipógina. Em Tiffaniella, o carposporófito desenvolve-se a partir de duas células auxiliares e forma-se uma célula de fusão proeminente, em forma de " $T$ ", englobando a célula hipógina, não havendo formação de filamentos involucrais.

As estruturas de reprodução de Spermothamnion speluncarum (Collins \& Herv.) M. Howe, referido para as regiões

Artigo recebido em 07/2007. Aceito para publicação em 01/2009.

${ }^{1}$ Laboratório de Algas Marinhas (LAMAR), Depto. Botânica, I.B., UFBA, Campus de Ondina, 40170-280, Salvador, BA.

${ }^{2}$ Herbário HUNEB, Depto. Ciências Exatas e da Terra, UNEB, Campus II, Alagoinhas, BA.

${ }^{3}$ Autor para correspondência: jmcnunes@ufba.br

${ }^{4}$ Instituto de Botânica, Seção de Ficologia, Av. Miguel Estéfano, 3687, 04301-902, São Paulo, SP. 
Nordeste, Sudeste e Sul do país foram estudadas por Guimarães \& Fujii (2001). As autoras verificaram que pelas características do carposporófito, a espécie deveria ser transferida para o gênero Ptilothamnion, passando a ser designada, $P$. speluncarum (Collins \& Herv.) D.L. Ballant.

Além da espécie acima, mais quatro espécies de Spermothamnion foram referidas para o litoral brasileiro: Spermothamnion investiens ( $\mathrm{P}$. Crouan \& H. Crouan in Schramm \& Mazé) Vickers e S. gorgonium (Mont.) Bornet, atualmente reconhecida como Tiffaniella gorgonea (Mont.) Doty \& Meñez. Ambas foram citadas para o estado do Espírito Santo (Oliveira Filho 1969, 1977), sendo a primeira também citada para o estado do Rio Grande do Norte, especificamente no Atol das Rocas (Oliveira Filho \& Ugadim 1976). Spermothamnion nonatoi A.B. Joly, foi citada para os estados de Santa Catarina (Horta 2000), São Paulo (Joly 1957, 1965; Ugadim 1976; Oliveira Filho \& Berchez 1978; Széchy 1996; Horta 2000), Rio de Janeiro (Pedrini 1980; Széchy 1996; Horta 2000), Espírito Santo (Guimarães 2006) e Bahia (Nunes 2005). Já Spermothamnion gymnocarpum M. Howe foi citada apenas para Pernambuco (Pereira \& Ugadim 1979).

Spermothamnion nonatoi foi descrito com base em material brasileiro coletado em São Vicente, estado de São Paulo (Joly 1957). Apesar de ter sido encontrada em várias regiões do litoral brasileiro, os exemplares coletados sempre estavam inférteis ou esporofíticos.

Este trabalho registra pela primeira vez, as fases sexuadas da espécie através de exemplares coletados no estado da Bahia.

\section{Material e Métodos}

O material estudado foi coletado no litoral baiano em diversas praias dos Municípios de Camaçari, Conde, Lauro de Freitas e Salvador. As localidades estão especificadas no material examinado. As coletas foram feitas no médiolitoral com auxílio de espátula, e no infralitoral através de draga do tipo "Holme". Todo o material coletado foi fixado em formalina a $4 \%$ diluída em água do mar, sendo as preparações coradas com solução aquosa de azul de anilina a $0,5 \%$, acidificada com HCL $1 \mathrm{~N}$. As medidas correspondem aos valores máximo e mínimo de cada estrutura.

Os estudos foram feitos em microscópio estereoscópico e óptico, marca Zeiss, observando-se a morfologia externa e interna das estruturas vegetativas e de reprodução. Fotomicrografias das estruturas foram feitas em microscópio de captura de imagem Zeiss.

O material identificado encontra-se depositado no Herbário Alexandre Leal Costa (ALCB) do Departamento de Botânica do Instituto de Biologia da Universidade Federal da Bahia.

\section{Resultados e Discussão}

Spermothamnion nonatoi A.B. Joly. Bolm. Fac. Ciênc. Let. Univ. S. Paulo 217 (Bot. 14): 140. 1957.

Fig. 1a-f, 2a-d

Talo filamentoso, unisseriado, ecorticado, com até $1 \mathrm{~mm}$ de altura, formado por eixo prostrado e ereto ramificado. Eixos eretos alternos e esparsamente ramificados, com células que medem 85-100 $\mu \mathrm{m} \times 284-420 \mu \mathrm{m}$ na região mediana; diâmetro dos filamentos principais e secundários mais ou menos uniformes. Eixos prostrados com células medindo 65-120 $\mu \mathrm{m}$ de diâmetro na região mediana. Rizóides unicelulares, com 23-57 $\mu \mathrm{m}$ de diâmetro, inseridos lateralmente nas células do eixo prostrado. Esporângios terminais em ramos curtos nas porções médias e superiores dos eixos eretos. A ramificação desses râmulos confere aspecto denso ao talo com esporângios. Tetrasporângios esféricos, com 60-80 $\mu \mathrm{m}$ de diâmetro, tetraedricamente divididos. Polisporângios ocasionalmente presentes, com oito esporos e com a mesma dimensão dos tetrasporângios.

Exemplares dióicos: Eixo feminino com ramo carpogonial subapical no filamento ereto. Este apresenta a célula apical mais curta e as duas células seguintes (célula subapical e célula hipógina) com altura aproximadamente igual, 


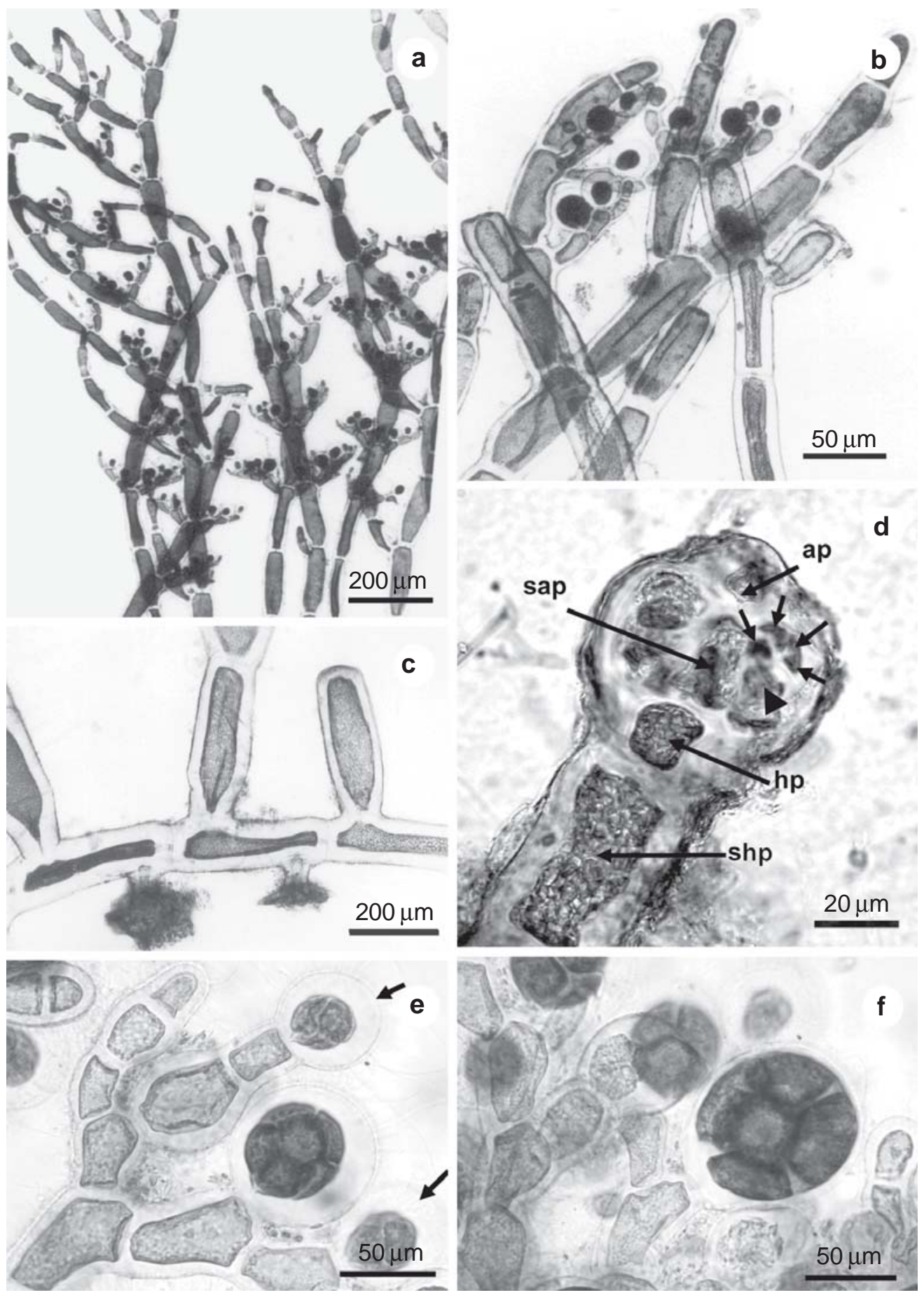

Figura 1 - Spermothamnion nonatoi: a. aspecto geral; b. detalhe dos eixos eretos com tetrasporângios; c. detalhe dos rizóides inseridos lateralmente nas células do eixo prostrado; d. sistema do procarpo (ap = célula apical; sap = célula subapical; hp = célula hipógina; shp = célula subhipógina). Células do ramo carpogonial (setas), célula suporte do ramo carpogonial (cabeça de seta); e. ramos com polisporângios jovens (seta); f. detalhe do polisporângio maduro.

Figure 1 - Spermothamnion nonatoi: a. habit; b. detail of erect axis with tetrasporangials; c. detail of rhizoids laterally inserted in cells of prostrate axis; d. procarp system (ap = apical cell; sap = subapical cell; $\mathrm{hp}=$ hipogine cell; shp = subhipogine cell). Cells from the carpogonial branch (arrows), support cell of carpogonial branch (head arrow); e. branch with polisporangials (arrow); f. detail of mature polisporangial. 
sendo a célula hipógina mais larga que a subapical. A célula subapical do eixo fértil forma três células periaxiais, sendo duas estéreis e uma fértil, que é a célula sustentadora do ramo carpogonial. A célula hipógina produz dois ramos curtos os quais se desenvolvem em ramos involucrais. O sistema do procarpo fica envolto por uma matriz gelatinosa comum. Estádios iniciais de formação do ramo carpogonial e das células estéreis associadas, assim como a formação da célula auxiliar após a fecundação, não observados nos exemplares estudados. Carposporófito maduro medindo $250-420 \mu \mathrm{m}$, envolto por dois filamentos involucrais, originados na célula subhipógina. A célula hipógina e a subhipógina são reconhecidas no carposporofito maduro. Espermatângios produzidos em corpos anteridiais elípticos, laterais, sésseis, inseridos adaxialmente no ápice dos eixos eretos, medindo 40-55 ×90-110 $\mu \mathrm{m}$

Material examinado: BRASIL. BAHIA: Camaçari, 1244'657'S × 3844'568'W, Cetrel, 6.XII.1996 (ALCB); 12'53'32”'S ×38'16'05”'W, Cetrel, 21.VII.2000 (ALCB); 1249'31"S ×3812'34W", Cetrel, 21.VII.2000 (ALCB); Arembepe, 6.XII.1996, J. M. C. Nunes (ALCB); Conde, Sítio do Conde, 4.XII.1997, J. M. C. Nunes (ALCB); Lauro de Freitas, Villas do Atlântico,

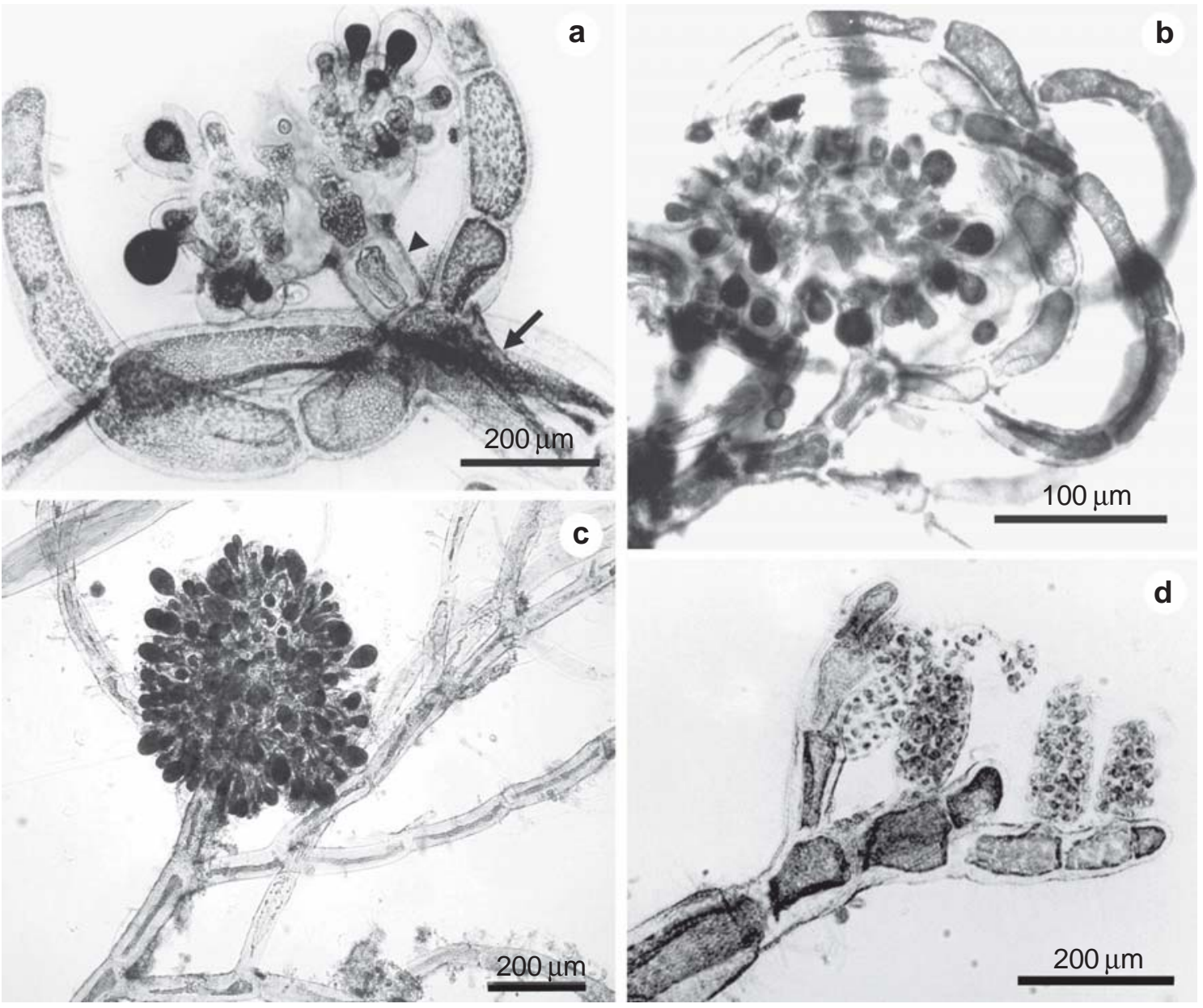

Figura 2 - Spermothamnion nonatoi: a. carposporófito em desenvolvimento, célula hipógina (cabeça de seta) e filamentos involucrais originados na célula subhipógina (seta); b e c. aspecto geral do carposporófito maduro; d. ramo com corpos anteridiais sésseis.

Figure 2 - Spermothamnion nonatoi: a. carposporophyte in development, hipogine cell (head arrow) and involucre filaments originated from the hipogine cell (arrow); b and c. general aspect of mature carposporophyte; d. branch with sessile anteridials bodies. 
24.V.1997, J. M. C. Nunes (ALCB); 5.XI.2002, J. M. C. Nunes, S. M. P. B. Guimarães \& M. T. Fujii (ALCB); Salvador, Stella Maris, 17.IV.2000, J. M. C. Nunes (ALCB); 27.III.2002 (ALCB); 15.III.2002 (ALCB); 4.XI.2002, J. M. C. Nunes, S. M. P. B. Guimarães \& M. T. Fujii (ALCB); 2.I.2003, J. M. C. Nunes (ALCB).

Distribuição no litoral brasileiro: Bahia, Espírito Santo, Rio de Janeiro, São Paulo e Santa Catarina.

Comentários: O material identificado como Spermothamnion nonatoi e citado para várias regiões do litoral brasileiro refere-se somente a exemplares inférteis ou esporofíticos. A Bahia parece representar o limite norte de distribuição desta espécie no Brasil. Esta distribuição pode ser mais ampla, porém, devido ao tamanho diminuto, os exemplares podem passar despercebidos em estudos florísticos. Entretanto, o estudo recente de Torres et al. (2004) não detectou exemplares da espécie no estado de Pernambuco.

O material proveniente da Bahia foi coletado no médio e infralitoral entre 13 e 34 $\mathrm{m}$ de profundidade, crescendo sobre Bryothamnion seaforthii (Turner) Kütz., B. triquetrum (S.G. Gmel.) M. Howe, Cryptonemia seminervis (C. Agardh) J. Agardh, Digenea simplex (Wulfen) C. Agardh e Gelidiopsis variabilis (Grev. ex J. Agardh) F. Schmitz e associada a Griffithsia caribaea Feldm.-Maz., G. schousboei Mont., Ptilothamnion speluncarum (Collins \& Herv.) D.L. Ballant. \& M.J. Wynne e Wrangelia argus (Mont.) Mont.

O presente trabalho descreve e ilustra pela primeira vez exemplares femininos e masculinos da espécie. A presença de polisporângios foi mencionada na descrição original (Joly 1957). Polisporângios foram descritos também para Spermothamnion cymosum (Harv.) De Toni (Gordon 1972; Womersley 1998).

Os gêneros da tribo Spermothamnieae divergiram segundo duas linhas evolutivas, baseadas na presença de uma ou duas células auxiliares e na perda subseqüente dos invólucros externo e interno do carposporófito (Huisman 1985). Em Ptilothamnion, o carposporófito desenvolve-se a partir de uma célula auxiliar única; a célula hipógina é bem mais longa que a célula subapical e produz dois ramos involucrais. Em Spermothamnion, o carposporófito desenvolve-se a partir de duas células auxiliares; a célula hipógina é levemente mais longa que a célula subapical, e os ramos involucrais são produzidos a partir da célula subhipógina (Womersley 1998).

Nos exemplares da Bahia o sistema do procarpo não pode ser estudado com detalhes, pois nos espécimens coletados este estádio já havia sido ultrapassado, restando aqueles que provavelmente não foram fecundados e se apresentavam em processo de degeneração. Predominavam os carposporófitos maduros. Os exemplares baianos concordam com as características do gênero Spermothamnion quanto à origem dos filamentos envoltórios a partir da célula subhipógina e por apresentarem a célula hipógina levemente mais longa que a célula subapical (Gordon 1972; Womersley 1998). Discordam em relação às características do gênero quanto à ausência, no carposporófito maduro, de célula de fusão proeminente que incorpora a célula hipógina, descrita por Gordon (1972) e Womersley (1998). O critério mais consistente para a confirmação do gênero Spermothamnion, ou seja, a presença de duas células auxiliares após a fecundação, não pode ser confirmado através deste trabalho, pois os exemplares portavam carposporófitos maduros, nos quais a etapa de formação das células auxiliares não podia mais ser observada.

Entretanto, como enfatizou Womersley (1998), estudos adicionais em outros táxons da tribo Spermothamnieae são necessários, para corroborar ou modificar os conceitos genéricos desenvolvidos por Gordon (1972) e outros autores, e baseados principalmente nas espécies australianas.

\section{Agradecimentos}

Ao PICDT - CAPES pela concessão da bolsa de Pós-Graduação, à Empresa Ambiental CETREL por ter cedido material proveniente do infralitoral. A segunda autora agradece a bolsa e auxílios concedidos pelo CNPq. 


\section{REFERÊNCIAS BIBLIOGRÁFICAS}

Gordon, E. M. 1972. Comparative morphology and taxonomy of the Wrangeliae, Shondylothamniae, and Spermothamniae (Ceramiaceae, Rhodophyta). Australian Jornal of Botany (Supl.) 4: 1-180.

Guimarães, S. M. P. B. 2006. A revised checklist of benthic marine Rhodophyta from the state of Espírito Santo, Brazil. Boletim do Instituto de Botânica 17: 143-194.

Guimarães, S. M. P. B. \& Fujii, M. T. 2001. Ptilothamnion speluncarum (Ceramiales, Rhodophyta): estudo das estruturas reprodutivas femininas confirma a presença do gênero no Brasil. Hoehnea 28: 297-305.

Horta, P. A. 2000. Macroalgas do infralitoral do sul e sudeste brasileiro. Tese de Doutorado. Universidade de São Paulo, São Paulo. 301p.

Huisman, J. M. 1985. Rhipidothamnion secundum gen. et sp. nov. and Spermothamnion miniatum sp. nov. (Ceramiales, Rhodophyta) from eastern Australia. Phycologia 24: 55-66.

Joly, A. B. 1957. Contribuição ao conhecimento da flora ficológica marinha da Baía de Santos e arredores. Boletim da Faculdade de Filosofia, Ciências e Letras da Universidade de São Paulo, série Botânica 14: 1-199.

Joly, A. B. 1965. Flora marinha do litoral norte do estado de São Paulo e regiões circunvizinhas. Boletim da Faculdade de Filosofia, Ciências e Letras da Universidade de São Paulo, série Botânica 21: 1-393.

Nunes, J. M. C. 2005. Rodofíceas marinhas bentônicas do estado da Bahia, Brasil. Tese de Doutorado. Universidade de São Paulo. 410p.

Oliveira-Filho, E. C. 1969. Algas marinhas do sul do estado do Espírito Santo (Brasil). I. Ceramiales. Boletim da Faculdade de Filosofia, Ciências e Letras da Universidade de São Paulo, série Botânica 26: 1-277.
Oliveira-Filho, E. C. 1977. Algas marinhas bentônicas do Brasil. Tese de LivreDocência. Universidade de São Paulo, São Paulo, 407p.

Oliveira-Filho, E. C. \& Berchez, F. A. S. 1978. Algas marinhas bentônicas da Baía de Santos - Alterações na flora no período de 1957-1978. Boletim de Botânica da Universidade de São Paulo 6: 49-59.

Oliveira-Filho, E. C. \& Ugadim, Y. 1976. A survey of the marine algae of Atol das Rocas. Phycologia 15: 41-44.

Pedrini, A. G. 1980. Algas marinhas bentônicas da Baía de Sepetiba e arredores (Rio de Janeiro). Dissertação de Mestrado, Universidade Federal do Rio de Janeiro, Rio de Janeiro, 397p.

Pereira, S. M. P. \& Ugadim, Y. 1979. Champia feldmannii Diaz-Piferrer and Spermothamnion gymnocarpum Howe, two new records from the Brazilian coast. Boletim de Botânica da Universidade de São Paulo 7: 39-42.

Széchy, M. T. M. 1996. Estrutura de bancos de Sargassum (Phaeophyta, Fucales) do litoral dos estados de Rio de Janeiro e São Paulo. Tese de Doutorado. Universidade de São Paulo, São Paulo, 159p.

Torres, J.; Pereira, S. M. P. \& YoneshigueValentin, Y. 2004. Ceramiaceae (Rhodophyta) de áreas recifais do estado de Pernambuco, Brasil. Hoehnea 31(2): 119-149.

Ugadim, Y. 1976. Ceramiales (Rhodophyta) do litoral sul do estado de São Paulo e do litoral do estado do Paraná (Brasil). Boletim de Botânica da Universidade de São Paulo 4: 133-172.

Womersley, H. B. S. 1998. The marine benthic flora of southern Australia. Rhodophyta - Part IIIC, Ceramiales - Ceramiaceae, Dasyaceae. State Herbarium of South Australia, Adelaide, 535p. 